NBER WORKING PAPER SERIES

\title{
DO FIRMS USE COUPONS AND IN-STORE DISCOUNTS TO STRATEGICALLY MARKET EXPERIENCE GOODS OVER THE CONSUMPTION LIFE-CYCLE? THE CASE OF CIGARETTES
}

\author{
Andrew Sfekas \\ Dean R. Lillard \\ Working Paper 19310 \\ http://www.nber.org/papers/w19310 \\ NATIONAL BUREAU OF ECONOMIC RESEARCH \\ 1050 Massachusetts Avenue \\ Cambridge, MA 02138 \\ August 2013
}

We gratefully acknowledge funding from the National Cancer Institute (Award 5 R01 CA120338-02 ) and expert research assistance from Eamon Molloy. The views expressed herein are those of the authors and do not necessarily reflect the views of the National Bureau of Economic Research., , ,

NBER working papers are circulated for discussion and comment purposes. They have not been peerreviewed or been subject to the review by the NBER Board of Directors that accompanies official NBER publications.

(C) 2013 by Andrew Sfekas and Dean R. Lillard. All rights reserved. Short sections of text, not to exceed two paragraphs, may be quoted without explicit permission provided that full credit, including $\mathbb{C}$ notice, is given to the source. 
Do Firms Use Coupons and In-store Discounts to Strategically Market Experience Goods Over the Consumption Life-Cycle? The Case of Cigarettes

Andrew Sfekas and Dean R. Lillard

NBER Working Paper No. 19310

August 2013

JEL No. I1,L1,L66

\begin{abstract}
Cigarettes are experience goods - most of their utility value only gets revealed when one consumes them. We hypothesize a three phase consumer life cycle for experience goods. Consumers initially do not know their utility from the good or their preferences for particular characteristics, and may initially choose the most familiar brand. In the second phase, they are informed about the good and may experiment with different brands. In the third phase, they may become loyal to one brand or exit the market. Firms could target price discounts for each phase, either to encourage experimentation (pay-to-switch), to retain customers (pay-to-stay), or to price-discriminate. We use market-level data on price, sales, in-store discounts, and coupon offers of 15 brands from 1995 to 2007 and individual-level data on brand choices from 1995 to 2004 to explore whether firms discount cigarettes in ways consistent with a life-cycle consumption model. We find that the three highest-selling brands primarily discount as price discrimination and pay-to-stay strategies, while smaller, specialty brands discount to encourage smokers to switch brands.
\end{abstract}

\author{
Andrew Sfekas \\ The Fox School of Business and Management \\ Temple University \\ Alter Hall \\ 1801 Liacouras Walk \\ Philadelphia, PA 19122 \\ andrew.sfekas@temple.edu \\ Dean R. Lillard \\ Department of Human Sciences \\ The Ohio State University \\ 1787 Neil Avenue \\ Columbus, $\mathrm{OH} 43210$ \\ and NBER \\ lillard.13@osu.edu
}




\title{
Do Firms Use Coupons and In-store Discounts to Strategically Market Experience Goods Over the Consumption Life-Cycle? The case of cigarettes
}

\author{
Andrew Sfekas \\ Dean R. Lillard \\ Temple University \\ sfekas@temple.edu \\ Ohio State University, DIW, and NBER \\ lillard.13@osu.edu
}

\begin{abstract}
Cigarettes are experience goods - most of their utility value only gets revealed when one consumes them. We hypothesize a three phase consumer life cycle for experience goods. Consumers initially do not know their utility from the good or their preferences for particular characteristics, and may initially choose the most familiar brand. In the second phase, they are informed about the good and may experiment with different brands. In the third phase, they may become loyal to one brand or exit the market. Firms could target price discounts for each phase, either to encourage experimentation (pay-to-switch), to retain customers (pay-to-stay), or to price-discriminate. We use market-level data on price, sales, in-store discounts, and coupon offers of 15 brands from 1995 to 2007 and individual-level data on brand choices from 1995 to 2004 to explore whether firms discount cigarettes in ways consistent with a life-cycle consumption model. We find that the three highest-selling brands primarily discount as price discrimination and pay-to-stay strategies, while smaller, specialty brands discount to encourage smokers to switch brands.
\end{abstract}

\section{Introduction}

Certain categories of goods are experience goods-most of their utility value is only revealed when one consumes them (Nelson 1970). Firms in markets for experience goods face consumers at several different stages of their consumption life-cycle. New consumers are uninformed about both the products within a category and 
about the utility of the entire category. Consumers at this pre-initiation stage may choose to follow the "herd" and experiment with the most popular brands, under the assumption that current consumers of the product may have useful information (Banerjee 1992). Following initiation of consumption, consumers gain information about the category as a whole and about their tastes for specific characteristics of the good. They then move to a different stage in their life cycle, in which they may be willing to seek brands that match their preferences more closely, or they may decide that they prefer not to consume products in the category. Finally, they may reach a point in their life cycle at which it no longer makes sense to consume the product.

The different stages of consumption suggest different pricing and promotional strategies for firms in this type of industry. Previous studies have shown that firms can gain an advantage (under some circumstances) by capturing market share among new consumers (Villas-Boas 2004), and that new entrants may need to provide discounts to new consumers to encourage them to try the product (Bergemann and Välimäki 2006). In order to attract the pre-initiation group, firms may find an advantage in having one heavily advertised and promoted brand with a large market share. This type of brand could encourage positive word-of-mouth (Bayus 1985; Keller and Fay 2009) and gain an edge with uninformed consumers. For the second group, firms may have an alternate goal of attracting targeted groups of consumers to niche brands. These niche brands may be produced by the same firms as the major brands (as is generally the case in this paper's analysis) or by smaller companies. Regardless, firms may wish to use promotions to pull consumers away from the major brands and into brands to which they will be more loyal.

To investigate how different types of promotions can target consumers at different points in their life cycle, we examine coupons and in-store discounts in the cigarette industry. The market for cigarettes is a natural case to study because life-cycle consumption patterns of cigarettes fit the stylized patterns for other experience goods. Most consumers start smoking one of three major brands: in 1999, 83.5 percent of smokers ages 18-24 named Marlboro, Camel, or Newport as their preferred cigarette (Kopstein 2001). In 2004 and 200677 percent of middle-school students and 86 percent of high school students who smoked named one of these three brands as their preferred cigarette (CDC 2009). In the middle of the typical smoking life-cycle, smokers either quit, remain loyal to the brand they started with, or switch to brands that better suit their tastes and/or that are cheaper. Among smokers age 26 and older, only 46.1 percent still prefer to smoke Marlboro, Newport, or Camel brands. The remaining smokers choose among other 
brands which firms markets to more narrowly defined demographic groups (e.g. Virginia Slims targets women), smokers with specialized tastes (e.g. the niche brand Gauloises uses very strong tobacco and is well-known for its unfiltered cigarettes), or to more price-sensitive consumers (e.g. GPC and Basic emphasize price over quality). After some time, smokers settle on a "final" brand. In the final stage of the typical smoking life-cycle, almost no smoker switches brands. They either quit or die as smokers of their chosen brand.

Given the above consumption patterns, we assign cigarette brands into one of three categories: brands that command high market share; lesser-known brands that target niche consumers; and lesser-known brands that target price-sensitive consumers. We refer to brands in these categories as "major," "minor," and "generic" brands respectively. ${ }^{1}$ Table 1 lists the brands we assign to each category.

-Table 1 about here -

One would expect that firms will offer different types of discounts for brands in each of the above categories. Firms selling one of the major brands may discount to existing customers to keep them from switching brands. As we describe below, firms can target existing customers if they offer discounts that can only be redeemed if a consumer buys a relatively large minimum amount of a given brand. Firms selling one of the minor or generic brands may discount to get smokers to try their brand. They will target smokers of other brands and may focus on relatively younger smokers of one of the major brands. To target these smokers, firms can offer discounts on small quantities and that can be redeemed immediately. To prevent existing customers from exploiting these discounts, the firms limit how many packs a consumer can buy at the discounted price.

To examine how discounting behavior relates to the goals of maintaining brand share or encouraging current consumers to try new brands, we analyze how sales and consumption vary with three types of discounts: coupons (clipped from magazines), in-store free pack discounts (e.g. buy 1 get 1 free), and in-store price discounts (e.g. \$1 off). We match market-level data on these discounts to brand-level sales data from supermarket scanners. The data track discounts and sales in each of 51 markets from 1994 to 2007. We match the same discount data to individual data from surveys administered between 1994 and 2004. These data, from a major marketing survey of individual consumers, measure whether or not a person smokes and, if he does, the brand he prefers to smoke. With these data we explore whether brand-level sales and individual brand choices systematically vary with temporal and geographic variation in discounts of different types.

\footnotetext{
${ }^{1}$ To avoid having empty cells of less common brands, we rank brands by sales volume over our sample period and retain only the top 15 brands.
} 
While existing studies do not directly examine whether firms use price promotions as suggested above, previous studies provide some empirical support for the proposition that price promotions affect sales in ways generally consistent with the above logic. In reviewing studies of price promotions, Blattberg et al. (1995) find that sales respond strongly to price promotions, but that the effect diminishes when promotions become more frequent. The evidence they review is inconclusive about whether price promotions affect sales in the long run or whether promotions increase sales in the short run primarily because the promotions induce consumers of other brands to switch or if the promotions induce new consumers to start. In a meta-analysis, DelVecchio et al. (2006) find mixed evidence about the dynamic effects of price discounts. They find that effects of discounts depend on whether the discounts are attached to a service or a packaged good, whether the brand faces a large number of competitors, and whether consumers are familiar with the brand. In a study of firm behavior, Allender \& Richards (2012) find that firms offer more frequent but less generous promotions when the firm sells a brand to which customers are more rather than less loyal. Nevo \& Wolfram (2002) investigate promotions offered by firms selling ready-to-eat breakfast cereals. They explore what type of strategies the promotions serve. They empirically test whether firms discount breakfast cereals as a strategy of price discrimination in a given period, to induce people to switch brands and/or to purchase repeated times, to smooth seasonal fluctuations in demand, or to help brand managers meet some performance objective. They find no evidence that firms discount as a way to price discriminate in a given period but do find some evidence that firms discount to encourage consumers of other cereal brands to switch to the discounted brand. ${ }^{2}$

Our study contributes to the literature on price promotions in several ways. First, we describe the characteristics of each of three common types of discounts in terms of how those characteristics allow firms to target groups of consumers in different life-cycle stages of consumption. Second, we describe strategies that firms might pursue with each type of discount and relate them to individuals' life-cycle patterns of consumption. Third, we use supermarket scanner data from 51 geographic markets to empirically describe the relationship between the number of discounts of particular types that firms offer for cigarette brands in the three categories. Finally, we use data from a national consumer survey to examine whether and how discounts affect the cigarette brands individuals choose to consume.

\footnotetext{
${ }^{2}$ They also find that couponing activity seems to increase towards the end of the fiscal year - a finding they interpret as consistent with the hypothesis that brand managers issue coupons to meet performance targets.
} 
Our aggregate and individual results suggest that firms use different types of discounts for particular types of brands to pursue one or more of both strategies. For major cigarette brands, firms use free pack discounts to retain less brand-loyal customers (pay-to-stay). An important component of this retention is in participation-free pack discounts are associated with greater smoking participation for older smokers, suggesting that they encourage older smokers not to quit. For minor cigarette brands, firms use free-pack and coupon discounts to encourage current smokers to experiment with their brand (pay-to-switch). The effect of minor brand discounts is greatest in the 26-34 year old age group-a group that will have experience with cigarettes, but may not yet be locked into a particular brand. The responsiveness of consumers by age group suggests that the life-cycle framework is correct: firms target younger smokers for brand-switching and older smokers for brand retention.

The remainder of the paper is structured as follows. In the next section we describe the three main strategies we examine and the concomitant patterns one should observe in our aggregate sales data and data on individual brand choices. In section 3 we describe the data. There we also estimate a descriptive model of the number of discounts issued for brands in each category to illustrate factors associated with variation in each type of discount for each type of brand category. This analysis reveals patterns consistent with the use of each type to target particular types of smokers. In section 4 we specify the equations we estimate and the expected patterns for the coefficients of interest. In section 5 and section 6 , we present results and relate them to the implications predicted by the competing models. Section 7 summarizes our results.

\section{Conceptual framework and hypothesis development}

To set the stage for the empirical analysis we review models that have been advanced to accommodate discounts as a profit maximizing strategy and the empirical patterns those models predict. Nevo \& Wolfram (2002) detail most of the relationships so we only briefly summarize them here. We relate each strategy to our proposed framework, in which manufacturers try to move some individuals to niche brands, while also offering promotions for major and generic brands to price discriminate. We also describe how each type of promotion may be more or less appropriate for each purpose. 


\subsection{Static price discrimination}

In the introduction, we describe a dynamic approach to discounting in which firms target different groups of consumers at different points in their life cycle. Additionally, certain discounts would affect consumers' future behavior by encouraging them to experiment with other brands. However, a simpler possibility is that discounts primarily serve a static price discrimination function. This section describes the expected patterns from such a use.

To our knowledge, ours is the first study to directly examine whether firms use price discounts as a static price discrimination strategy. To price discriminate, firms must have some market power. Although the industry is not a monopoly, previous research supports the hypothesis that cigarette firms do have some market power (Sumner 1981; Sullivan 1985; Keeler et al. 1996). ${ }^{3}$

Nevo \& Wolfram (2002) describe three patterns one should expect when a monopolist engages in static price discrimination. First, if a firm can price discriminate it will discount cigarettes for the most price sensitive consumers and charge other consumers more. Therefore one should observe more discounts when the average price is higher. Second, overall sales should be higher in periods that one observes more price discounts. By definition, a firm that pursues a static price discrimination strategy decides each period whether or not to discount prices. Consequently, current period sales should not vary with past period discounts. Finally, if a firm pursues a pure price discrimination strategy, the discounts should have little effect on brand choice, since all firms target the discounts only at price-sensitive smokers of their own brand. Note that, because the industry developed generic cigarette brands to specifically appeal to price sensitive smokers, discounts on generic cigarette brands are likely to be a price discrimination strategy.

The above description suggests that price discrimination should lead to the following patterns:

Hypothesis 1. Sales will be higher in a period that a firm offers more discounts.

Hypothesis 2. Current period sales will not vary with past discounts.

Hypothesis 3. Current period brand choice will not vary with past discounts (though it may vary with current discounts).

Hypothesis 4. In a given period, price will be positively associated with the number of discounts.

\footnotetext{
${ }^{3}$ In 2010 three firms sold nearly 85 percent of all cigarettes bought in the United States (Maxwell 2011).
} 
Although retailers may choose the actual sale price, manufacturers could affect the retail price by changing the wholesale price. As in Agrawal (1996), retailers would then partially pass through any wholesale price discounts to the consumer.

\subsection{Pay-to-switch and pay-to-stay}

Corts (1998) and Shaffer \& Zhang (2000) offer a dynamic explanation for discounts that can be adapted to our proposed life cycle model. In both models, firms target price discounts at either their own customers (Shaffer \& Zhang refer to this as "pay-to-stay") or other firms' customers ("pay-to-switch"). In Corts's model, relative to the case when firms do not price discriminate, consumers pay a lower average price if one firm employs the "pay-to-stay" strategy. In Shaffer \& Zhang's model, however, prices may be higher for some consumers even when one firm pays its customers to stay. We do not attempt to distinguish between these models in our analysis. We use Shaffer \& Zhang's pay-to-stay/pay-to-switch framework here, since its logic is more intuitive.

A key feature that determines whether a firm adopts a pay-to-stay or pay-to-switch strategy is the extent and depth of customers' loyalty to a brand. Sometimes analysts use a brand's share of market sales as a proxy for the loyalty of consumers for that brand. By that metric, younger smokers 18-25 are quite loyal customers of the dominant cigarette brands-Marlboro, Camel, and

Newport-because those brands accounted for a high share of all sales. Among older smokers, these three brands account for a smaller share of sales. The falling market shares suggest that a smoker's loyalty for these three brands erodes as smokers age.

If cigarette brands were marketed independently, manufacturers might use a pay-to-stay strategy to keep consumers from switching to other (minor or generic) brands. However, the manufacturers of the major brands also have several minor brands in their portfolio. While pay-to-switch makes sense as a strategy for minor brands, pay-to-stay might not be an optimal strategy for major brands if they were paying consumers not to switch to a minor brand. On the other hand, pay-to-stay would make sense as a strategy if these firms were paying consumers not to quit.

The pay-to-stay strategy involves a period-by-period choice (i.e. the consumer decides not to switch in one period, but may choose differently in the following period). If price discounts serve a pay-to-stay role, one would expect them to have a positive effect on brand choice in the current period, but have no effect in subsequent periods. However, there may be a dynamic effect if consumers eventually become locked into a brand. We expect that only major brands will use this strategy. This leads us to our next hypotheses: 
Hypothesis 5. Discounts for major brands will increase current sales but will not affect future sales.

Hypothesis 6. Discounts for a major brand will raise the probability that a person chooses the discounted brand in the current period but will not affect the probability of the brand choice in subsequent periods.

Of the three discount types, free pack offers may more effectively prevent consumers from exiting the market than do other types of discounts because cigarettes are addictive and the consumer must exercise some willpower to cease smoking. A smoker might be less likely to quit smoking if he uses a free pack offer because doing so implies that the smoker will have extra packs in his hands. For that reason, we propose an additional hypothesis:

Hypothesis 7. Firms selling major brands will use free pack discounts to keep consumers from exiting the market.

Firms may also use discounts to induce smokers to switch brands. Firms may be able to take advantage of some consumers' willingness to search for a better "fit", especially since switching behavior may be asymmetric (Blattberg, Briesch, and Fox 1995). A firm will benefit if they induce consumers to switch because they will gain consumers who are less likely to be enticed away by competitors' strategies (Dick and Basu 1994). For a firm that sells both major and minor brands, one strategy might be for the firm to target its own consumers of the major brand who are less brand loyal (perhaps because the major brand doesn't satisfy their preferred tastes). If the firm can get such customers to switch to one of the firm's own smaller targeted brands, it gains a set of consumers of the minor brand who are more loyal and thus ensures a more stable flow of revenue.

In the framework of Shaffer \& Zhang (2000), offering discounts to switch brands is referred to as "pay-to-switch." The firm might not observe any given smoker's tastes, but could offer discounts to encourage a broad set of smokers to experiment with the brand. Some fraction of the smokers will discover the brand matches their tastes and they will then become loyal customers. We expect that such brands are more often represented among the "minor" brands because they tend to occupy special niches. We would therefore expect to see minor brands employ a pay-to-switch strategy.

This discussion leads to the following hypothesis:

Hypothesis 8. Firms will offer discounts on minor brands as a pay-to-switch strategy. Successful pay-to-switch discounts will raise the probability a smoker buys the discounted brand and will increase current and future sales. 
By extension, the logic of our proposed consumption life-cycle implies that consumers will be most susceptible to switching when they are younger; over time consumers settle on a preferred brand and subsequently respond less to promotions. This logic leads to one more hypothesis:

Hypothesis 9. Younger consumers will respond more to minor brand discounts than older consumers.

Anderson \& Song (2004) also suggest that firms pursuing this strategy may find it optimal to lower their price at the same time as a discount offer. This suggests the following additional hypothesis:

Hypothesis 10. Holding constant the number of outstanding discount offers, the price of cigarettes will be lower when more discounts are offered on minor brands.

An additional consideration is the type of discount that would be appropriate for pay-to-switch. Ault et al. (2000) and Busse et al. (2006) show that different methods of discounting are not equivalent. A coupon is likely to be passed through to consumers at a higher rate than an in-store discount. Coupons also have the advantage that they can be targeted to some degree (potentially by placing them in magazines read by the desired demographic). Buy-one-get-one-free offers may not be suitable as a switching device, since consumers' primary uncertainty is whether they will like the new brand. An extra free pack would simply be an offer of two goods with uncertain quality.

This leads to one more hypothesis:

Hypothesis 11. Minor brands will use coupons to encourage brand switching, rather than other types of price promotion.

\subsection{Expected empirical patterns}

In the aggregate, the static price discrimination and pay-to-stay strategies predict similar empirical patterns: current sales should increase when current discounts increase, but current sales should not vary with the number of discounts firms offer in previous periods. The expected pattern differs for a pay-to-switch strategy. Current period sales should increase with pay-to-switch discounts in both the current and past periods. Past period discounts should raise current period sales because, to be a long run solution, a firm must successfully expand its market and keep the new smokers loyal or it must successfully steal customers from another firm who remain loyal at least one more period. 
Similar patterns should be evident in the analyses of brand choice in the individual data. If firms use pay-to-stay strategies, current discounts should increase the probability of choosing a brand, while past discounts should have little or no effect. If firms use discounts for static price discrimination, we would only see this pattern if the discounts caused people to remain in the market. By contrast, if firms use pay-to-switch strategies, both current and lagged discounts should raise the probability that a person smokes the discounted brand.

Table 2 summarizes the expected patterns in aggregate and individual smoking data associated with each strategy. ${ }^{4}$

- Table 2 about here -

Our hypotheses also predict which types of discounts should fit these patterns, and which age groups should be most affected. In those cases, the patterns in table 2 should fit for those specific discounts and age groups.

\section{Data}

We draw data from three sources. We draw aggregate data from AC Nielsen's ScanTrack on cigarette brand sales from 1995 to 2007 in 51 metropolitan markets. We draw individual data from the Simmons National Consumer Surveys (NCS) on the brands individuals smoke. We pool data from the cross-sectional NCS administered between 1995 and 2004. To both the aggregate and individual data, we append data on coupons that cigarette marketers issued in print media in up to 75 metropolitan markets. The coupon data, collected by Marx Promotion Intelligence, vary over time and across geographic markets.

In each market AC Nielsen samples stores with total annual sales of at least $\$ 1$ million. However, the sample excludes convenience stores and WalMart stores. The data, measured over four week periods, include all information encoded on a product's "Uniform Product Code" label (the UPC is the barcode now ubiquitous on all products). UPC labels include detailed information on the quantity, packaging, brand, flavor, and many other characteristics of the product. The UPC also contains information on discounts associated with a product. ${ }^{5}$

\footnotetext{
${ }^{4}$ Others suggest but we do not try to test two other strategies firms might pursue when they offer discounts. Warner \& Barsky (1995) provide evidence to support the hypothesis that firms discount more on weekends because it costs price-sensitive shoppers less to search on those days. Aguirregabiria (1999) propose that firms discount to manage inventory and perhaps to reduce wastage costs.

${ }^{5}$ We ignore promotional "giveaways" - discounts that give customers a complimentary item because it is difficult to know either their retail value or how consumers value them.
} 
We aggregate all data for a given brand to create measures for each quarter of each year. ${ }^{6}$ To construct a measure of per-capita sales of each brand, we sum the number of packs of a given brand sold in each market in each quarter and then divide by the population in the market. To compute an average price without discounts, we divide total sales revenue by total packs sold. For that computation we sum revenue and quantity sold for all cigarettes of a given brand that were sold without any type of discount. We adjust the resulting prices for inflation (to real 2008 dollars). To measure discounts in each quarter, we create an indicator that equals " 1 " if a given UPC code included a price or quantity discount. We then sum the indictor for all UPC codes of each brand in each quarter. This measure corresponds to a count of the total number of each type of discount available for any product within a particular brand in a market and time period.

We measure coupons as the total number of new coupons issued within a particular quarter. We track new issues only because coupons often remain in effect for several weeks after they are originally issued.

It is important to note that our scanner data probably capture purchases of smokers who are older than the average smoker. The AC Nielsen sample excludes cigarettes sold at WalMart and convenience stores. For brands that older smokers buy, the omission does not matter much but it is reflected in the share of total sales of brands favored by younger smokers. For example, according to the report Tobacco Use in America (Kopstein 2001), in 1999 Marlboro had a market share of 56.6 percent among 18-25 year olds and a share of 35.3 percent among smokers older than 25. In our supermarket scanner data, Marlboro accounts for 31 percent of all sales. The share of total sales of other cigarette brands in the scanner data match closely with the share those brands command in nationally representative data of overall sales.

Despite the above caveats, our supermarket scanner data are superior in other ways to data used in previous studies. First, with those data we are able to construct a time series of detailed brand-specific price data for each quarter from 1995 through 2007. Most studies characterize the price of cigarettes in much less detail. ${ }^{7}$ Second, we have detailed data on three different types of discounts: in-store free pack discounts, in-store cents-off discounts, and coupons. Finally, we supplement our analysis of the aggregate sales data with individual-level data on brand choice that complements and enriches the analysis.

\footnotetext{
${ }^{6}$ We do not differentiate between different types of the same brand (e.g. "king-size" versus "regular" Marlboros).

${ }^{7}$ Most studies use the time series of annual average cigarette prices in each state reported in the Tax Burden on Tobacco (Orzechowski and Walker 2008).
} 
The Simmons National Consumer Survey (NCS) is a biannual random-digit dial phone survey of individuals age 18 and older. ${ }^{8}$ On average each NCS includes information on about 15,000 respondents. With sample weights, these data are nationally representative of the US population living in the 48 states (excluding Alaska and Hawaii). The surveys collect detailed information on respondents' demographic characteristics, income, cigarette consumption (including brands smoked) and smoking behavior. To append time and geographic specific information on discounts in each market, we use survey information to identify those respondents who live in one of the areas that AC Nielsen labels as "Designated Marketing Areas" or DMAs. DMAs generally correspond to metropolitan areas but specifically Nielsen defines DMA as the geographic area within which television viewers can receive television signals from the major television broadcast stations. Because the NCS uses the DMA to define geographic areas, we can match data on coupon offers and cigarette sales from supermarket scanner data to individual NCS respondents. Data on each smoker's preferred brand is collected in every survey between 1995-2004.

- Table 3 about here-

Table 3 presents summary statistics for each of our variables of interest by brand category. On average, the major brands command the highest price and generics sell at the lowest price. In terms of absolute numbers, major brands offer the most free pack and coupon promotions. Generics offer the next largest number in those categories, and the largest number of cents-off discounts. Minor brands offer the fewest of all three promotion types. The probability that a firm offered at least one coupon was similar across the brand categories, but minor brands offered the fewest.

Table 4 presents summary statistics from the NCS sample. Approximately 20 percent of the sample were current smokers, close to the national average found in other samples. Smokers consumed an average of about 17 cigarettes per day, slightly less than one pack. Seven percent of the sample reported their race as black, which is below the national average, while about 18 percent reported Hispanic ethnicity, which is close to the national average. Reported household income is higher than the national average.

- Table 4 about here -

\footnotetext{
${ }^{8}$ In 1995 and 1996 Simmons administered only one survey per year.
} 


\subsection{Multi-variate description}

In addition to the summary statistics that describe each sample, we use multivariate analysis to explore patterns in the type of discounts firms offer (free packs, cents-off, coupons). We estimate the relationship between the number of promotions of a particular type, price, current and future taxes, other types of discounts for the same brand and discounts of all for other brands. These estimates will provide preliminary evidence on our model through hypotheses 4 and 10 . Hypothesis 4 states that if discounts are used for static price discrimination, then price and number of discounts should be positively related. Hypothesis 10 states that if discounts are used for pay-to-switch, then price and number of discounts should be negatively related or unrelated.

For every cigarette brand $i$ sold in market $j$ in period $t$ we estimate the following equation:

$$
\begin{aligned}
\text { DiscountType }_{i j t}= & \beta_{0}+\beta_{1} \text { Price }_{i j t}+\beta_{2} \text { Tax }_{j t}+\beta_{3} \text { Tax }_{j, t+1} \\
& +\beta_{3} \text { DiscountOthTypes }_{i j t}+\beta_{4} \text { Discount }_{o j t}+\psi_{i j}+\tau_{t}+\varepsilon_{i j t}
\end{aligned}
$$

where, in market $j$ in period $t$, DiscountType $e_{i j t}$ refers to the number of discounts of a given type offered for brand $i$, Pricet tijt $_{\text {refers to the undiscounted }}$ price of brand $i$, DiscountOthTypes ${ }_{i j t}$ refers to the other types of discounts offered for brand $i$, and Discount ${ }_{o j t}$ refers to discounts offered by other brands $o$ that are in the same brand category and therefore compete with brand $i$. As before Discount is a vector of variables that describe how many promotions of other types a firm concurrently offers on the brand in question. Of course the vector does not include the discount of the type that is being modeled. We also include market and time-period fixed effects.

Table 5 presents results from Equation 1. Among major and generic brands, more coupons are issued in periods when price is higher. These associations are consistent with a static price discrimination strategy, in which firms target more price-sensitive consumers with coupons (allowing the firms to raise the price for other consumers). For minor brands, price is negative but insignificant, which is still consistent with (though not strong evidence for) hypothesis 10 .

By contrast, across all three brand categories, firms issue fewer free pack discounts in markets or periods when the undiscounted price is higher. One possible reason for this result is that free-pack offers differ from cents-off discounts because firms must discount in discrete and set amounts. For example, a

"buy-one-get-one-free" offer constitutes a price discount of 50 percent. As the price 
increases, the opportunity cost of issuing another free pack discount rises relative to a discount of cents-off because firms cannot offer fractional free-pack discounts. Consequently, when overall demand or costs increase sufficiently, firms offer fewer free-pack discounts for all cigarette brands, regardless of type.

Discounts should be related to cigarette taxes because states and the federal government impose an excise tax that levies the same per pack tax on all cigarette brands. When the tax changes, firms can use discounts to affect the relative price of a particular brand that selected groups pay. In markets or periods when the current tax is higher, firms selling major brands of cigarettes absorb some of the current cigarette tax by issuing more free pack and more cents-off discounts. Firms selling minor brands of cigarettes issue more free pack discounts but fewer cents-off discounts.

When the tax is going to rise in the next quarter, firms selling major brands issue fewer free pack discounts but more cents-off discounts. ${ }^{9}$ Future taxes do not affect the number of discounts of other types for minor or generic cigarette brands.

The relationships shown in Table 5 between current and future taxes and free pack and cents-off discounts for major brands are consistent with both static price discrimination and pay-to-stay strategies. Issuing more free pack and cents-off discounts in response to higher current taxes is equivalent to a firm absorbing some of the tax increase. That act could either reflect paying one's customers to stay, or static price discrimination. However, firms issue fewer free pack discounts for major brands when the future tax is going to be higher.

This association suggests firms use the free-pack discounts as a pay-to-stay strategy because paying customers to stay is less profitable when future demand falls. If firms cannot pass on all of the tax increase, a higher future tax implies a lower profit margin.

Firms issue more cents-off discounts for major brands when both the current tax is higher (consistent with static price discrimination and pay-to-stay) and when the future tax is going to be higher. Note that when states increase cigarette taxes, they almost always simultaneously impose a "floor stock tax" that is equal the difference between the future and current cigarette tax. That tax is levied on all cigarettes held in stock on the date the new tax rate takes effect. The latter association suggests that firms use cents-off discounts as a way to lower inventories ahead of a tax increase.

For minor brands, a higher current tax leads firms to issue more free pack discounts but fewer cents-off discounts. The former association is consistent with

\footnotetext{
${ }^{9}$ Because of the legislative process states use to raise taxes, firms usually know well in advance when the tax will increase.
} 
static price discrimination and pay-to-stay strategies. The latter association is a puzzling result that is not consistent with any of the strategies we consider. In all other cases, the future cigarette tax does not affect the coupons, free pack, or cents-off discounts firms offer on minor cigarette brands.

- Table 5 about here -

The pattern of coefficients on the other types of own-brand discounts in Table 5 suggests either that firms selling major brands of cigarettes treat discounts of each type as substitutes for each other, or that they pursue only one type of strategy at a time. In general, a firm offers fewer discounts of a particular type in markets or periods the firm offers more of the other two types of discounts. For firms selling minor brands of cigarettes, cents-off discounts substitute for coupons. For firms selling generic brands of cigarettes, cents-off discounts complement coupon discounts and free pack discounts substitute for cents-off discounts.

The more detailed descriptive results in Table 5 provides the first evidence that firms use particular types of discounts on particular types of brands to implement one or more of the above three strategies. We now turn to the aggregate sales models and models of individual brand choice.

\section{Methods and Estimation Equation}

In this section, we specify equations that relate discounts to aggregate measures of consumption and individual brand choice. We relate the models and their coefficients to each of the hypotheses specified in Section 2.

\subsection{Model of per-capita sales}

Hypotheses 1, 2, 5, and 8 can be tested using brand-level aggregate per capita sales data. Hypotheses 1 and 2 state that if firms use discounts for static price discrimination, then discounts will affect current sales, but not future sales.

Hypothesis 5 is essentially the same as hypotheses 1 and 2, but applies to major brands pursuing a pay-to-stay strategy: discounts should affect current but not future sales for major brands. Finally, hypothesis 8 states that minor brands will use discounts as a pay-to-switch strategy, and thus discounts should increase both current and future sales.

We specify a simple model of per capita sales:

$$
C_{b j t}=\beta_{0}+\beta_{1} \text { Price }_{b j t}+\beta_{2} \text { Discount }_{b j t}+\beta_{3} \text { Discount }_{b j, t-1}+\psi_{b j}+\tau_{t}+\varepsilon_{b j t}
$$


where subscripts $b$ refers to the brand, $j$ refers to the market, and $t$ refers to the quarter. The dependent variable, $C_{b j t}$, is per capita sales of brand $b$ in market $j$ in quarter $t$. Price $_{b j t}$ is the undiscounted price of the brand. Discounts $s_{b j t}$ is a vector of the three brand-specific discount variables. We include a fixed efffect, $\psi_{b j}$, for each brand $b$ in a given market $j$ and a fixed effect $\tau_{t}$ for time period $t$. We estimate separate models for each brand category. We estimate the model using ordinary least squares.

The expected results are that $\beta_{1}$ will be negative and significant in all models, $\beta_{2}$ will be positive and significant in all models, and $\beta_{3}$ will be positive and significant for minor brands but insignificant for major and generic brands. Collectively, this pattern would indicate that major and generic brands pursue either pay-to-stay or static price discrimination strategies and minor brands pursue pay-to-switch strategies.

An alternative model would be the rational addiction model of Becker, Grossman, \& Murphy (1994). The rational addiction model accounts for the addictive nature of cigarettes by including a lagged consumption term, and accounts for forward-thinking consumers by including a lead consumption term. This specification is appropriate if consumers are rational and forward looking. Empirically, results are qualitatively the same from the specification that includes leads and lags of consumption and our simpler model. We use the simpler specification above because rational addiction is not a focus of this paper.

\subsection{Model of Individual Brand Choice}

Hypotheses 6, 8, 9, and 11 can be tested using individual consumer-level data on brand choices. Hypothesis 6 states that major brands use discounts for pay-to-stay, and therefore discounts should positively affect current, but not future, brand choice. Hypothesis 8 states that minor brands use discounts for pay-to-switch, and therefore discounts should positively affect both current and future brand choice. Hypothesis 9 states that younger consumers should be more likely to switch brands, so that discounts should have a greater effect on this group. Finally, hypothesis 11 states that minor brands should primarily use coupons for pay-to-switch.

To investigate whether and how discounts affect the brand an individual chooses, we estimate a conditional logit model. We use data on the brand an individual currently smokes, the brand's price, and the number of discounts the firm offers for each brand. We specify the basic brand-choice model as:

$$
\begin{aligned}
\operatorname{Pr}\left(\text { Brand }_{i j t}\right)= & F\left(\beta_{0}+\beta_{1} \text { Price }_{j t}+\beta_{2} \text { Discount }_{j t}+\beta_{3} \text { Discount }_{j, t-1}\right. \\
& \left.+\beta_{4} X_{i j t}+\nu_{i}+\psi_{j}+\tau_{t}+\varepsilon_{i j t}\right)
\end{aligned}
$$


where subscripts $i$ refers to the individual, $j$ refers to the market, and $t$ refers to the quarter. Brand $d_{i j t}$ equals 1 when consumer $i$ chooses brand $j$ in period $t$ and 0 otherwise, Price $_{j t}$ is the price of the brand in market $j$ in period $t$, and $X_{i j t}$ is a vector of demographic characteristics. The vector Discount ${ }_{j t}$ includes all three types of discounts, and interactions between these types of discounts and two indicators that identify brands in the minor and generic brand categories. These interaction terms allow the effect of discounts to vary across brand categories. The individual effect $\nu_{i}$ is conditioned out, leaving the conventional conditional logit framework. We also include brand fixed effects and time trends for each type of brand. ${ }^{10}$

One of our hypotheses is that brand-switching will diminish with age. We therefore estimate some of our models separately for different age groups.

We also examine smoking participation to test whether firms offer discounts to expand the market by either encouraging new smokers or retaining older smokers. We focus separately on individuals between the ages of 18 and 25 and on individuals older than 25, since almost all smokers start before the age of 26 . To investigate whether discounts affect this decision, we estimate whether the sum of discounts of each type (across all major brands) affect the probability that an individual chooses to smoke.

The smoking participation model is given by:

$$
\begin{aligned}
\operatorname{Pr}\left(\text { Smoke }_{i j t}\right)= & F\left(\gamma_{0}+\gamma_{1} \text { Price }_{j t}+\gamma_{2} \text { Discount }_{j t}+\gamma_{3} \text { Discount }_{j, t-1}\right. \\
& \left.+\gamma_{4} X_{i j t}+\nu_{i}+\psi_{j}+\tau_{t}+\varepsilon_{i j t}\right)
\end{aligned}
$$

where Price $_{j t}$ is the simple average of the price of the three major brands. The vectors Discount $_{j t}$ and Discount Dit-1 $_{j, 1}$ include three discount measures for current and past periods respectively. The three variables in each vector are the sum of discounts of a particular type across all three brands in the major brand category.

\section{$5 \quad$ Aggregate results}

Table 6 presents results from the aggregate sales models of major brands (column 1), minor brands (column 2) and generic brands (column 3). All models include brand-market and time-period fixed effects. We estimate separate models for each brand type. 11

\footnotetext{
${ }^{10}$ When we include brand-specific time trends, the model does not converge.

${ }^{11}$ Full results are available on request.
} 
The aggregate model provides only limited evidence for most of the hypotheses. For major brands, both current and lagged free pack discounts are negatively associated with per capita sales. This could indicate that firms offer more discounts when sales drop for other reasons, but does not provide support for any of the hypotheses. A similar pattern holds for free pack offers in the generic brand model. Cents-off discounts for major brands, however, do appear to have a positive and significant association with sales, suggesting that they may serve a price discrimination or pay-to-stay purpose. However, this result does not rule out inventory management as an explanation.

In the model of sales of minor brands, the quantity sold varies positively with the number of coupons issued and the number of free pack discounts in both the current and past quarter, and with the number of free pack offers in the current quarter. This suggests that both could serve a dynamic function such as pay-to-switch.

Finally, for generic cigarettes, no discount aside from free packs is significantly associated with per capita sales in the current period.

- Table 6 about here -

These results provide some evidence for pay-to-switch for minor brand discounts, and no evidence in support of static price discrimination or pay-to-stay for any of the brands. However, the aggregate brand-level data may not capture substitution between brands, and will not reflect non-supermarket purchases. Thus, the individual data may be a better indicator of discounting effects.

\section{$6 \quad$ Individual analyses}

Table 7 presents results from the individual brand choice model. ${ }^{12}$ The model uses discounts on major brands as the reference category and allows discounts to differentially affect the probability a smoker chooses a minor or generic cigarette brand.

- Table 7 about here -

Because the interaction terms make it difficult to focus on the effect of discounts of a particular type, we use the results from Table 7 to compute the total direct effect of each discount type. In Figure 1 we plot the correlation between each type of discount and the probability a person smokes a cigarette brand in the major, minor, or generic brand categories (running left to right respectively for each type of discount).

\footnotetext{
${ }^{12}$ We discuss only the results on discount variables. Full results are available on request.
} 
The results are consistent with several of our hypotheses. Consistent with hypothesis 6 , current free pack discounts are associated with a higher probability of choosing a brand for the major brands, but past free pack discounts are not. As we noted in the conceptual framework, free pack discounts would be better suited for pay-to-stay than other types because the consumer has additional product on hand as a result of the purchase.

Consistent with hypothesis 8 , free pack and coupon discounts for minor brands fit the pattern for pay-to-switch-both current and past discounts are positively associated with a higher probability of choosing the brand. However, only the coupon results provide evidence for 11; we expected that coupons would be more suitable than free packs for pay-to-switch because the consumer may prefer a more straightforward discount in case the brand is not a good match.

- Figure 1 about here -

A person is more likely to smoke a major brand of cigarettes when firms offer more cents-off discounts for major cigarette brands in the current period. Past cents-off discounts on major brands do not affect the probability an individual smokes a major brand. This pattern is consistent with price discrimination or pay-to-stay strategies. The probability a smoker chooses a minor or generic brand is uncorrelated with either current or past cents-off discounts on those brands.

Our last analysis explores whether discounting in current and past periods differentially affects the probability of smoking participation of smokers by age. Table 8 presents selected coefficient estimates on current and past period discounts of each type from the model of smoking participation. The first column presents results from the sample of people age 18 to 25 years old. The second column presents results for the sample that is 26 and older.

- Table 8 about here -

The results in Table 8 generally suggest that discounts do not serve a pay-to-switch strategy that is targeted at younger smokers. ${ }^{13}$ In the younger sample, we find marginally significant and positive associations only for past period free pack discounts for generic brands and coupon discounts for minor brands. We note again that new smokers rarely choose to smoke generic or minor brands. Consequently, it is unclear what behavior these associations reflect. Further, though point estimates on some of the coefficients from the younger sample are larger than the point estimtes in the older sample, the standard errors are also large. One cannot reject the hypothesis of equality in the coefficients across the two samples. The results provide no evidence of age patterns in the participation model and thus no evidence that firms selectively discount to youth.

\footnotetext{
${ }^{13}$ If such a strategy targeted non-smoking youth, it might be a pay-to-start strategy.
} 
The relatively few statistically significant associations on discounts from the sample of older respondents are mixed. Respondents older than 26 are more likely to smoke in markets and periods when firms offer more free-pack discounts for major brands in the current period and more coupons for major brands in the past period. But they are less likely to smoke when firms offer more free-pack discounts for minor brands in the current period and more coupons for generic brands in the previous period. The first set of associations could arise if those discounts convince smokers to not quit. It is unclear what might explain the second set of results.

The results overall suggest that minor brands use free pack discounts and coupons to encourage switching, and that the largest effect is in the 25-34 year old age group. These results are consistent with our life cycle model of consumer behavior, since this age group has some experience but may not have settled on a brand. Major brands appear to use free pack discounts to encourage consumers to stay, and in particular may use these discounts to encourage older smokers not to quit. It is less clear what purpose cents-off discounts serve, though they may function as a mechanism for inventory management. Additionally, it is not clear what purpose discounts serve for generic brands.

\section{Conclusion}

In the consumption of experience goods, consumers may follow life-cycle patterns in which they start with a popular brand, experiment with niche brands, and finally settle on a single brand or drop out of the market. Firms selling each of these brands could take this life cycle of consumption into account when setting prices or targeting price promotions. This paper investigated the use of three types of discounts in cigarette markets-in-store free pack giveaways (buy-one-get-one-free), in-store cents-off discounts, and coupons-to determine whether empirical patterns suggested that firms target discounts to reflect the consumer's life cycle.

Our analysis focused on the cigarette market. We examined patterns in data on the number of discounts offered of each type, aggregate sales, individual brand choice, and individual smoking participation. We explored whether those patterns were consistent with the hypothesis that firms use these promotions to price discriminate, to keep existing consumers (pay-to-stay) or to attract new consumers from other brands (pay-to-switch). Although we were not able to determine the strategies behind several types of discounts, we were able to identify evidence consistent with each of the strategies. Further, the empirical evidence suggested that each of these strategies affected consumers at the expected point in their life cycle: older consumers appear to be affected more by pay-to-stay strategies, while 
younger, but somewhat experienced, consumers appear to be affected more by pay-to-switch strategies. Also in keeping with our hypotheses, the larger brand discounts were a better fit for pay-to-stay, while the smaller (minor) brand discounts were more consistent with pay-to-switch.

More broadly, we find evidence consistent with the hypothesis that firms use price promotions for pay-to-stay and pay-to-switch strategies, as suggested by Shaffer \& Zhang (2000). We found that dominant brands were more likely to pursue pay-to-stay strategies, while fringe brands tended to use pay-to-switch strategies. The brands pursuing pay-to-switch strategies were those that compete on product characteristics, rather than price. For minor brands, firms must convince consumers to try their brand in the first place, in the hopes of finding a better match than their current brand. We found no evidence that per capita sales or individual brand choices changed when firms issued any type of discount (past or present) for generic brands of cigarettes. The absence of a pattern was surprising because firms developed generic brands to specifically appeal to price sensitive consumers. But we find no pattern to suggest that firms discount generic brands of cigarettes as a price discrimination strategy.

In terms of the type of discount, we found some expected patterns and some unexpected patterns. Coupons appear to serve a pay-to-switch role for minor brands-an expected result, since it should be easier to target a coupon than other types of discount. However, free packs also appear to serve this purpose, an unexpected result since the consumer would be left with extra product if the brand does not match the consumer's preferences. Free packs for major brands appear to serve a pay-to-stay function, and may serve the purpose of retaining older consumers in the market. This is intuitively appealing, since a consumer who is trying to quit may have more difficulty if the firm is able to give that consumer more of the product.

Of course firms may use discounts to pursue other strategies in multiple combinations. When selling a dominant brand, a firm may be in a position to pursue a simple price discrimination strategy in conjunction with a pay-to-stay strategy. More generally, some firms sell both major and minor brands. For those firms it will likely be optimal to pursue multiple strategies. While certain consumers will seek out other brands that may better match their preferences, others may simply choose to exit the market entirely when the cost is too high. By targeting specific types of discounts at this group of consumers, a firm may entice them to continue to smoke.

Overall it is clear that firms use discounts of different types with different brands to pursue a complex and nuanced set of strategies, and that these strategies 
appear to target consumers at different points in their life cycles. While our data do not allow us to test whether firms use the discounts to attract new smokers, it seems plausible that they might. Alternatively, they may attract new smokers by maintaining a critical mass in their largest (major) brand. The interplay between moving consumers to niche brands, where they may be more loyal, and keeping a critical mass in the major brand, to capture new consumers, may be an important topic for future research.

\section{References}

Agrawal, D. 1996. "Effect of brand loyalty on advertising and trade promotions: A game theoretic analysis with empirical evidence." Marketing Science 15 (1): $86-108$.

Aguirregabiria, Victor. 1999. "The Dynamics of Markups and Inventories in Retailing Firms." The Review of Economic Studies 66 (2): 275-308.

Allender, WJ, and TJ Richards. 2012. "Brand loyalty and price promotion strategies: An empirical analysis." Journal of Retailing 88 (3): 323-342.

Anderson, ET, and I Song. 2004. "Coordinating price reductions and coupon events." Journal of Marketing Research 41 (4): 411-422.

Ault, RW, TR Beard, DN Laband, and RP Saba. 2000. "Rebates, inventories, and intertemporal price discrimination." Economic Inquiry 38 (4): 570-578.

Banerjee, AV. 1992. "A simple model of herd behavior." Quarterly Journal of Economics 107 (3): 797-817.

Bayus, B. 1985. "Word of mouth: The indirect effects of marketing efforts." Journal of Advertising Research 25 (3): 31-40.

Becker, Gary S, Michael Grossman, and Kevin M Murphy. 1994. "An Empirical Analysis of Cigarette Addiction." American Economic Review 84 (3): 396-418.

Bergemann, D, and J Välimäki. 2006. "Dynamic pricing of new experience goods." Journal of Political Economy 114 (4): 713-743.

Blattberg, RC, R Briesch, and EJ Fox. 1995. "How promotions work." Marketing Science 14 (3): G122-G132.

Busse, M, J Silva-Risso, and F Zettelmeyer. 2006. "\$1,000 cash back: The pass-through of auto manufacturer promotions." American Economic Review 96 (4): 1253-1270. 
CDC. 2009. "Cigarette Brand Preference Among Middle and High School Students Who Are Established Smokers-United States, 2004 and 2006." Morbidity and Mortality Weekly Report 58 (5): 112-115.

Corts, Kenneth S. 1998. "Third-Degree Price Discrimination in Oligopoly: All-Out Competition and Strategic Commitment." The RAND Journal of Economics 29 (2): 306-323.

DelVecchio, D, and DH Henard. 2006. "The effect of sales promotion on post-promotion brand preference: A meta-analysis." Journal of Retailing 82 (3): 203-213.

Dick, AS, and K Basu. 1994. "Customer loyalty: Toward an integrated conceptual framework." Journal of the Academy of Marketing Science 22 (2): 99-113.

Keeler, Theodore, Teh-Wei Hu, Paul Barnett, and Hai-Yen Sung. 1996. "Do cigarette producers price discriminate by state? An empirical analysis of local cigarette pricing and taxation." Journal of Health Economics 15 (4): 499-512.

Keller, E, and B Fay. 2009. "The role of advertising in word of mouth." Journal of Advertising Research 49 (2): 154-158.

Kopstein, A. 2001. Tobacco Use in America: Findings from the 1999 National Household Survey on Drug Abuse. Rockville, MD: Substance Abuse and Mental Health Administration.

Maxwell, JC. 2011. The Maxwell Report: Year End \& Fourth Quarter 2010 Sales Estimates for the Cigarette Industry. Richmond: John C Maxwell, jr.

Nelson, P. 1970. "Information and consumer behavior." Journal of Political Economy 78 (2): 311-329.

Nevo, Aviv, and Catherine Wolfram. 2002. "Why Do Manufacturers Issue Coupons? An Empirical Analysis of Breakfast Cereals." The RAND Journal of Economics 33 (2): 319-339.

Orzechowski and Walker. 2008. The Tax Burden on Tobacco. Orzechowski and Walker.

Shaffer, Greg, and Z John Zhang. 2000. "Pay to Switch or Pay to Stay: Preference-Based Price Discrimination in Markets with Switching Costs." Journal of Economics and Management Strategy 9 (3): 397-424.

Sullivan, D. 1985. "Testing hypotheses about firm behavior in the cigarette industry." Journal of Political Economy 93 (3): 586-598. 
Sumner, Daniel. 1981. "Measurement of monopoly behavior: an application to the cigarette industry." Journal of Political Economy 89 (5): 1010-1019.

Villas-Boas, JM. 2004. "Consumer learning, brand loyalty, and competition." Marketing Science 23 (1): 134-145.

Warner, EJ, and RB Barsky. 1995. "The timing and magnitude of retail store markdowns: Evidence from weekends and holidays." Quarterly Journal of Economics 110 (2): 321-352. 
Table 1: Brands in Major, Minor, and Generic Categories

\begin{tabular}{ccc} 
Major & Minor & Generic \\
\hline Marlboro & Kool & Doral \\
Newport & Pall Mall & Basic \\
Camel & Winston & GPC \\
& Salem & \\
& Merit & \\
& Parliament & \\
& Virginia Slims & \\
& Benson \& Hedges & \\
& Carlton
\end{tabular}

Table 2: Expected Pattern of Association between Discounts and Outcomes Under Four Hypotheses, by timing of promotion

\begin{tabular}{lcc} 
Strategy & Aggregate per capita sales & Individual brand choice \\
\hline Static price discrimination & & \\
Current discounts & positive & positive \\
Past discounts & zero & zero \\
Pay-to-stay & & \\
Current discounts & positive & positive \\
Past discounts & zero & zero \\
Pay-to-switch & & \\
Current discounts & positive & positive \\
Past discounts & positive & positive
\end{tabular}


Table 3: Summary Statistics-Brand-level Data

\begin{tabular}{lccc} 
& Major brands & Minor brands & Generic brands \\
\hline Price & 2.98 & 2.85 & 2.39 \\
& $(1.03)$ & $(1.06)$ & 0.88 \\
Number of Discounts & & & \\
Free packs & 4.38 & 0.78 & 0.85 \\
& $(5.07)$ & $(2.19)$ & $(1.84)$ \\
Cents-off & 0.33 & 0.14 & 0.56 \\
& $(1.43)$ & $(0.82)$ & $(2.35)$ \\
Coupons & 0.11 & 0.02 & 0.04 \\
& $(0.77)$ & $(0.17)$ & $(0.29)$ \\
Any new coupon & 0.03 & 0.01 & 0.03 \\
& $(0.18)$ & $(0.12)$ & $(0.17)$ \\
\hline
\end{tabular}

Notes: Data measured per calendar year quarter. Price in 2008 dollars.

Table 4: Summary Statistics-Individual Data

\begin{tabular}{lcccc} 
& Mean & Std. Dev & Min & Max \\
\hline Current smoker & 0.195 & 0.396 & 0 & 1 \\
Cigarettes per day & 16.57 & 10.43 & 2.5 & 40 \\
Black & 0.071 & 0.256 & 0 & 1 \\
Hispanic & 0.177 & 0.381 & 0 & 1 \\
Female & 0.549 & 0.498 & 0 & 1 \\
Age & 46.45 & 16.25 & 18 & 77 \\
Less than high school & 0.126 & 0.331 & 0 & 1 \\
High school grad & 0.267 & 0.442 & 0 & 1 \\
Some college & 0.262 & 0.440 & 0 & 1 \\
College grad & 0.328 & 0.470 & 0 & 1 \\
Married & 0.649 & 0.477 & 0 & 1 \\
Divorced & 0.092 & 0.289 & 0 & 1 \\
Widowed & 0.063 & 0.243 & 0 & 1 \\
Separated & 0.020 & 0.140 & 0 & 1 \\
Real household income/10000 & 8.309 & 6.156 & 0.224 & 30.898 \\
\hline
\end{tabular}

Notes: $\mathrm{N}=192,541$ individuals overall (36,174 smokers). 


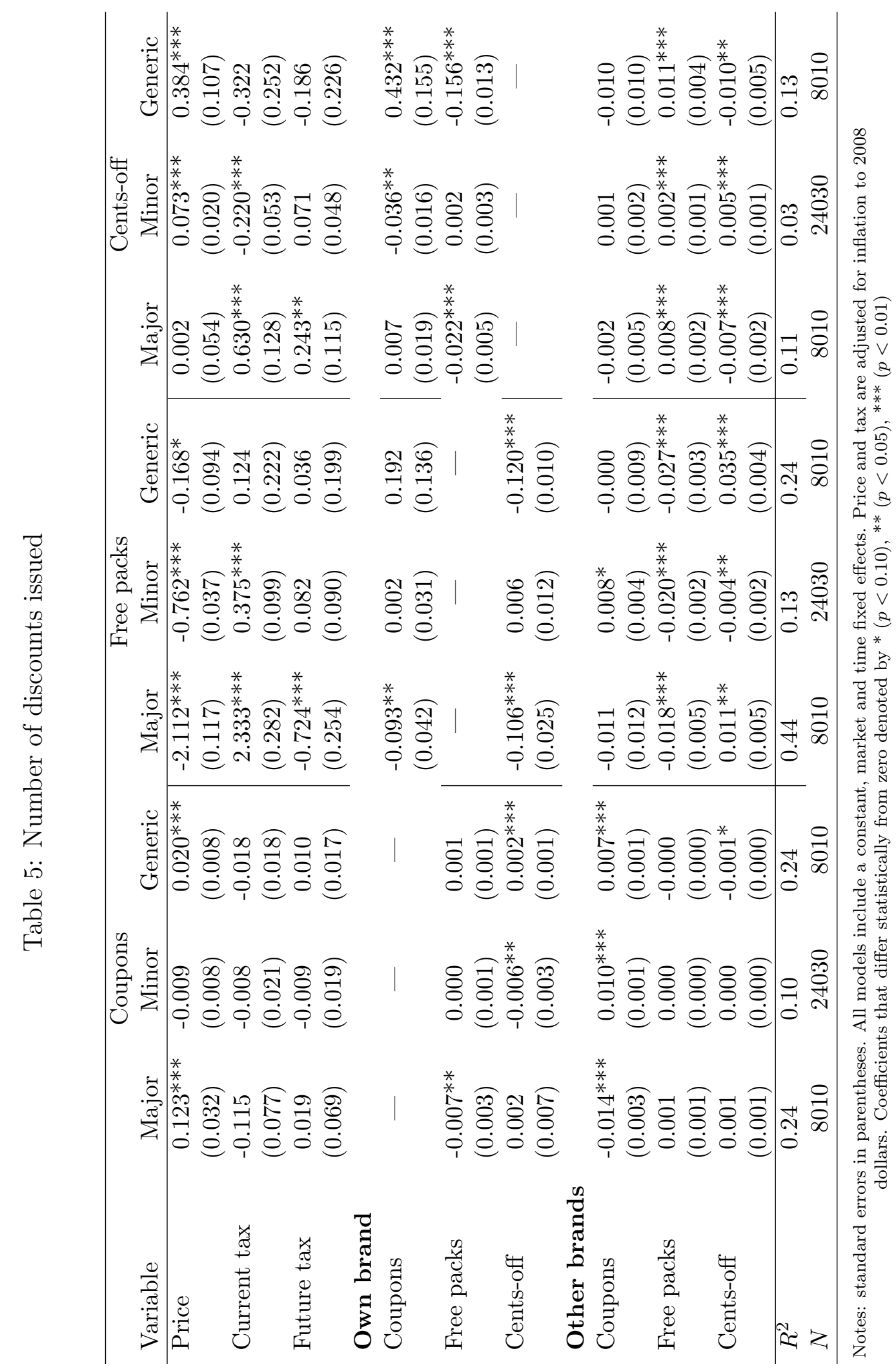


Table 6: Per Capita Cigarette Sales, by brand category

\begin{tabular}{lccc} 
Variable & Major brands & Minor brands & Generic brands \\
\hline Price & -0.015 & -0.006 & 0.002 \\
& $(0.007)^{*}$ & $(0.000)^{* *}$ & $(0.003)$ \\
\# of free pack offers & -0.006 & 0.004 & -0.002 \\
& $(0.001)^{* *}$ & $(0.000)^{* *}$ & $(0.001)^{*}$ \\
\# of cents-off offers & 0.008 & -0.001 & 0.001 \\
& $(0.004)^{*}$ & $(0.001)$ & $(0.001)$ \\
\# of new coupon offers & 0.002 & 0.012 & -0.006 \\
& $(0.004)$ & $(0.001)^{* *}$ & $(0.006)$ \\
Lag \# of free pack offers & -0.009 & 0.002 & 0.000 \\
& $(0.001)^{* *}$ & $(0.000)^{* *}$ & $(0.001)$ \\
Lag \# of cents-off offers & 0.005 & 0.005 & -0.002 \\
& $(0.004)$ & $(0.001)^{* *}$ & $(0.001)^{*}$ \\
Lag \# of new coupon offers & 0.001 & 0.011 & -0.009 \\
& $(0.004)$ & $(0.001)^{* *}$ & $(0.006)$ \\
$N$ & 7854 & 23562 & 7854 \\
\hline
\end{tabular}

Notes: standard errors in parentheses. All models include a constant, corresponding discount offers for other brands in each category, price and the lagged and lead value of total per capita sales of all cigarettes in each market. Sales measured per 1,000 population. Price is adjusted for inflation to 2008 dollars. Coefficients that differ statistically from zero denoted by $*(p<0.10),{ }^{* *}(p<0.05), * * *(p<0.01)$ 
Table 7: Conditional logit coefficients on probability of brand choice (smokers only)

\begin{tabular}{|c|c|c|c|c|}
\hline & All ages & Ages $18-24$ & Ages 25-34 & Ages ¿34 \\
\hline \multicolumn{5}{|l|}{ Current period offers } \\
\hline \multirow[t]{2}{*}{ Free packs } & 0.010 & 0.015 & 0.009 & 0.011 \\
\hline & $(0.002)^{* *}$ & $(0.005)^{* *}$ & $(0.004)^{*}$ & $(0.002)^{* *}$ \\
\hline \multirow[t]{2}{*}{ Free packs X minor } & 0.005 & -0.021 & 0.045 & 0.001 \\
\hline & $(0.006)$ & $(0.021)$ & $(0.017)^{* *}$ & $(0.007)$ \\
\hline \multirow[t]{2}{*}{ Free packs $\mathrm{X}$ generic } & -0.008 & -0.044 & -0.010 & -0.007 \\
\hline & $(0.005)$ & $(0.027)$ & $(0.015)$ & $(0.006)$ \\
\hline \multirow[t]{2}{*}{ Cents-off } & 0.044 & 0.057 & 0.040 & 0.039 \\
\hline & $(0.006)^{* *}$ & $(0.014)^{* *}$ & $(0.013)^{* *}$ & $(0.008)^{* *}$ \\
\hline \multirow[t]{2}{*}{ Cents-off X minor } & -0.026 & -0.028 & -0.042 & -0.020 \\
\hline & $(0.009)^{* *}$ & $(0.035)$ & $(0.026)$ & $(0.011)$ \\
\hline \multirow[t]{2}{*}{ Cents-off X generic } & -0.047 & -0.099 & -0.075 & -0.035 \\
\hline & $(0.015)^{* *}$ & $(0.077)$ & $(0.039)$ & $(0.017)^{*}$ \\
\hline \multirow{2}{*}{ Coupons } & -0.023 & -0.042 & -0.009 & -0.011 \\
\hline & $(0.011)^{*}$ & $(0.026)$ & $(0.025)$ & $(0.015)$ \\
\hline \multirow[t]{2}{*}{ Coupons X minor } & 0.088 & 0.166 & 0.144 & 0.061 \\
\hline & $(0.019)^{* *}$ & $(0.073)^{*}$ & $(0.051)^{* *}$ & $(0.023)^{* *}$ \\
\hline \multirow[t]{2}{*}{ Coupons X generic } & 0.076 & 0.176 & 0.088 & 0.062 \\
\hline & $(0.058)$ & $(0.238)$ & $(0.160)$ & $(0.066)$ \\
\hline \multicolumn{5}{|l|}{ Previous period offers } \\
\hline \multirow[t]{2}{*}{ Lag free packs } & 0.015 & 0.013 & 0.019 & 0.015 \\
\hline & $(0.002)^{* *}$ & $(0.005)^{* *}$ & $(0.004)^{* *}$ & $(0.002)^{* *}$ \\
\hline \multirow[t]{2}{*}{ Lag free packs X minor } & 0.014 & 0.033 & 0.024 & 0.009 \\
\hline & $(0.006)^{*}$ & $(0.020)$ & $(0.018)$ & $(0.007)$ \\
\hline \multirow[t]{2}{*}{ Lag free packs $\mathrm{X}$ generic } & -0.009 & 0.016 & -0.005 & -0.011 \\
\hline & $(0.005)$ & $(0.025)$ & $(0.015)$ & $(0.006)$ \\
\hline \multirow[t]{2}{*}{ Lag cents-off } & -0.005 & -0.011 & 0.012 & -0.002 \\
\hline & $(0.007)$ & $(0.016)$ & $(0.015)$ & $(0.009)$ \\
\hline \multirow[t]{2}{*}{ Lag cents-off X minor } & 0.005 & -0.037 & 0.010 & 0.002 \\
\hline & $(0.009)$ & $(0.037)$ & $(0.026)$ & $(0.011)$ \\
\hline \multirow[t]{2}{*}{ Lag cents-off $\mathrm{X}$ generic } & -0.010 & 0.050 & 0.014 & -0.024 \\
\hline & $(0.017)$ & $(0.067)$ & $(0.041)$ & $(0.020)$ \\
\hline \multirow[t]{2}{*}{ Lag coupons } & 0.007 & 0.023 & 0.024 & -0.008 \\
\hline & $(0.011)$ & $(0.024)$ & $(0.023)$ & $(0.016)$ \\
\hline \multirow[t]{2}{*}{ Lag coupons X minor } & 0.060 & -0.027 & 0.118 & 0.067 \\
\hline & $(0.023)^{* *}$ & $(0.096)$ & $(0.060)$ & $(0.027)^{*}$ \\
\hline \multirow[t]{2}{*}{ Lag coupons X generic } & -0.018 & -0.412 & 0.142 & 0.006 \\
\hline & $(0.071)$ & $(0.402)$ & $(0.189)$ & $(0.079)$ \\
\hline$N$ & $1,514,345$ & 156,359 & 298,067 & $1,059,919$ \\
\hline
\end{tabular}

Notes: standard errors in parentheses. All models include brand fixed effects. Coefficients that differ statistically from zero denoted by $*(p<0.10),{ }^{* *}(p<0.05),{ }^{* * *}(p<0.01)$ respectively. 
Figure 1: Estimated Correlation between Discounts and the Probability a Smoker Chose a Major, Minor, or Generic Cigarette Brand, by discount type
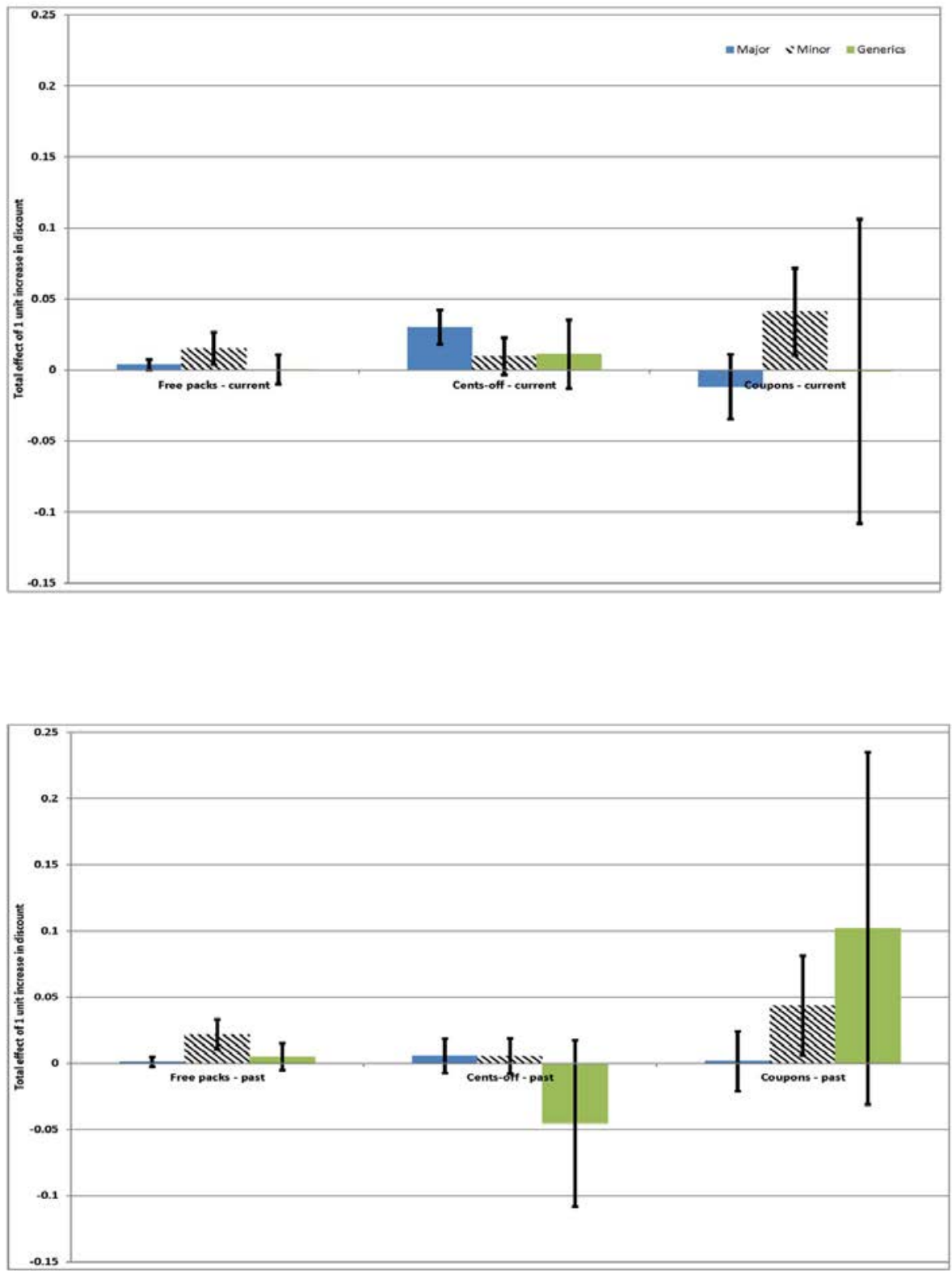
Table 8: Selected Coefficients from Probit Model of Smoking Participation, by age group

\begin{tabular}{|c|c|c|}
\hline Variable & Age 18 to 25 & Age $26+$ \\
\hline \multicolumn{3}{|l|}{ Current period discounts } \\
\hline Cents-off major & $\begin{array}{c}0.0068 \\
(0.0063)\end{array}$ & $\begin{array}{c}0.0010 \\
(0.0022)\end{array}$ \\
\hline Cents-off minor & $\begin{array}{c}0.0011 \\
(0.0043)\end{array}$ & $\begin{array}{l}-0.0013 \\
(0.0013)\end{array}$ \\
\hline Cents-off generic & $\begin{array}{c}0.0084 \\
(0.0062)\end{array}$ & $\begin{array}{l}-0.0001 \\
(0.0021)\end{array}$ \\
\hline Free packs major & $\begin{array}{c}0.0027 \\
(0.0032)\end{array}$ & $\begin{array}{l}0.0035^{* * *} \\
(0.0011)\end{array}$ \\
\hline Free packs minor & $\begin{array}{l}-0.0065^{* *} \\
(0.0027)\end{array}$ & $\begin{array}{l}-0.0025^{* * *} \\
(0.0009)\end{array}$ \\
\hline Free packs generic & $\begin{array}{c}0.0016 \\
(0.0046)\end{array}$ & $\begin{array}{l}-0.0002 \\
(0.0015)\end{array}$ \\
\hline Coupons major & $\begin{array}{c}0.0002 \\
(0.0127)\end{array}$ & $\begin{array}{l}-0.0023 \\
(0.0043)\end{array}$ \\
\hline Coupons minor & $\begin{array}{l}-0.0030 \\
(0.0046)\end{array}$ & $\begin{array}{c}0.0001 \\
(0.0016)\end{array}$ \\
\hline Coupons generic & $\begin{array}{l}-0.0327 \\
(0.0488)\end{array}$ & $\begin{array}{c}0.0123 \\
(0.0162)\end{array}$ \\
\hline \multicolumn{3}{|l|}{ Past period discounts } \\
\hline Cents-off major & $\begin{array}{l}-0.0065 \\
(0.0067)\end{array}$ & $\begin{array}{l}-0.0025 \\
(0.0024)\end{array}$ \\
\hline Cents-off minor & $\begin{array}{c}0.0040 \\
(0.0049)\end{array}$ & $\begin{array}{c}0.0010 \\
(0.0015)\end{array}$ \\
\hline Cents-off generic & $\begin{array}{l}-0.0087 \\
(0.0071)\end{array}$ & $\begin{array}{l}-0.0026 \\
(0.0024)\end{array}$ \\
\hline Free packs major & $\begin{array}{c}0.0006 \\
(0.0030)\end{array}$ & $\begin{array}{l}-0.0016 \\
(0.0010)\end{array}$ \\
\hline Free packs minor & $\begin{array}{c}0.0019 \\
(0.0028)\end{array}$ & $\begin{array}{c}0.0015 \\
(0.0009)\end{array}$ \\
\hline Free packs generic & $\begin{array}{c}0.0086^{*} \\
(0.0047)\end{array}$ & $\begin{array}{c}0.0012 \\
(0.0016)\end{array}$ \\
\hline Coupons major & $\begin{array}{c}0.0117 \\
(0.0104)\end{array}$ & $\begin{array}{l}0.0078^{* *} \\
(0.0035)\end{array}$ \\
\hline Coupons minor & $\begin{array}{l}0.0083^{* *} \\
(0.0042)\end{array}$ & $\begin{array}{c}0.0019 \\
(0.0014)\end{array}$ \\
\hline Coupons generic & $\begin{array}{l}-0.0448 \\
(0.0454)\end{array}$ & $\begin{array}{l}-0.0308^{* *} \\
(0.0155)\end{array}$ \\
\hline$N$ & 8996 & 86765 \\
\hline PseudoR2 & 0.060 & 0.080 \\
\hline
\end{tabular}

Notes: standard errors in parentheses. All models include a constant, the average price of major, minor, and generic brands of cigarettes, race, sex, employment status, educational attainment, marital status, household income, age, age squared, whether the respondent is the head of household, the age of the household head, market fixed effects, and a linear time trend. Prices and income31te adjusted for inflation to 2008 dollars. Coefficients that differ statistically from zero denoted by $*(p<0.10),{ }^{* *}(p<0.05),{ }^{* * *}(p<0.01)$ 